http://jmscr.igmpublication.org/home/

ISSN (e)-2347-176x ISSN (p) 2455-0450

crossref DOI: https://dx.doi.org/10.18535/jmscr/v7i7.141

\title{
Prevalence of substance abuse among students of SMS Medical College Jaipur, Rajasthan
}

\author{
Authors \\ Nikita Sharma, Kusum Gaur, Rekha Shekawat*, Suresh Kewalramani \\ *Corresponding Author \\ Rekha Shekhawat
}

\begin{abstract}
Background: Globally, there are 2 billion alcohol users, 1.3 billion smokers and 185 million are drug users. These are accounting for 12.4\% of all deaths worldwide. The doctors are vulnerable to substance abuse due to their ready accessibility to the substance of abuse. Medical training is identified as full of stress and it is also observed that students undergo tremendous stress during various years of medical training and post graduation.. Repeated use of alcohol and tobacco can effect judgment of actions. This could be disastrous if substance abusers are medical professionals who have direct dealing with human lives.

Methods: A cross sectional study was conducted at SMS medical college in Jaipur city, capital of Rajasthan. A pre designed structured questionnaire was used to interview 809 medical students who were willing to participate.

Results: Prevalence of smoking in MBBS students was found to be $15.2 \%$. The prevalence of alcohol consumption was found to be $20.3 \%$.It was observed that smoking and alcohol intake was more common in post graduate students $(28.6 \%$ \& $48.1 \%$ respectively) followed by interns .

Conclusions: Prevalence of substance abuse among medical college students was high. Students preferred alcohol products and tobacco most. Hosteller students are more likely to be exposed to substance abuse.

Keywords: Medical students, Prevalence, Substance abuse.
\end{abstract}

\section{Introduction}

Globally, there are 2 billion alcohol users, 1.3 billion smokers and 185 million are drug users. These are accounting for $12.4 \%$ of all deaths worldwide. $^{(1)}$ The doctors are vulnerable to substance abuse due to their ready accessibility to the substance of abuse. ${ }^{(2)}$ Medical students not only represent a young and responsible population in the society, but are the pillars of health. Medical training is identified as full of stress and it is also observed that students undergo tremendous stress during various years of medical training. ${ }^{(3)}$ Medical professionals are in fact more prone to be affected as they faced with patients suffering and deaths on a regular basis and academic pressure, workload, sleep deprivation, student abuse, lack of social activities may further contribute to this decline in students' mental health. ${ }^{(4-6)}$ Hence, identifying the rates and risks of substance use and the social patterns that promote or inhibit use during medical education is an increasingly important task. Hence the present study is carried out to assess the prevalence of alcohol and substance abuse among medical students. 


\section{Methodology}

A cross-sectional study was conducted on the medical students of SMS Medical College, Jaipur for a period of six months from July 2017 to January 2018 using pre designed structured questionnaire. The aim was to collect data regarding their demographic profile and their smoking and drinking habits if any. Permission of the Principal of the institute was obtained and an informed verbal consent was also obtained from the students. The study tool was distributed to the students at the end of their respective classes, for which permission was also taken from the concerned subject's teacher taking the lecture. The students were asked to complete the questionnaire within twenty minutes and return them in the same session. Likewise Interns and postgraduate students were approached in OPD's and wards and their respective sheets were collected the next day. In this manner 926 students out of 1047 were available at the time of data collection. Out of that 874 responded and 809 completely filled sheets were available for data compilation including 502 undergraduate students, 112 interns 195 postgraduate students.

Inclusion Criteria: All the students who were present in the class on the day of data collection and gave the consent were included in the study

\section{Exclusion Criteria}

a) Students who refused to participate.

b) Students who were unavailable/absent at the time of data collection.

c) Students who submitted incomplete or blank sheets were excluded from the study.

\section{Results}

Table 1 Socio demographic variables of students

\begin{tabular}{|c|c|c|}
\hline Variable & Frequency $(n=809)$ & Percentage $(\%)$ \\
\hline \multicolumn{3}{|l|}{ Religion } \\
\hline Hindu & 770 & 95.8 \\
\hline Muslim & 32 & 3.9 \\
\hline Christian & 7 & 0.8 \\
\hline \multicolumn{3}{|l|}{ Type of Family } \\
\hline Nuclear Family & 594 & 73.4 \\
\hline Joint Family & 187 & 23.1 \\
\hline Broken & 28 & 3.5 \\
\hline \multicolumn{3}{|l|}{ Gender } \\
\hline Male & 401 & 49.6 \\
\hline Female & 408 & 50.5 \\
\hline
\end{tabular}

\begin{tabular}{|l|c|c|}
\hline \multicolumn{2}{|l|}{ Class } \\
\hline $\begin{array}{l}\text { Under } \\
\text { Graduates }\end{array}$ & 502 & 62.1 \\
\hline Interns & 112 & 13.8 \\
\hline Post Graduates & 195 & 24.1 \\
\hline Residence & & \\
\hline Hosteller & 627 & 77.5 \\
\hline Non Hosteller & 182 & 22.5 \\
\hline
\end{tabular}

As shown in table 1 Majority of the participants were Hindu (95.8\%) and $73.4 \%$ belonged to nuclear family. There was almost equal representation of study participants in gender perception with males and females as $49.6 \%$ and $50.5 \%$ respectively. $62.1 \%$ subjects were studying in MBBS, followed by Post graduates (24.1\%) and Interns (13.8\%). Considering current residential details; subjects residing in hostel were present in greater number $(77.5 \%)$

Table 2 Categories of the students

\begin{tabular}{|l|c|c|}
\hline Students & $\begin{array}{c}\text { Alcohol } \\
\text { Consumption }\end{array}$ & Smoking \\
\hline MBBS & $102(20.3)$ & $76(15.2)$ \\
\hline Interns & $36(32.1)$ & $27(24.6)$ \\
\hline Post Graduates & $94(48.1)$ & $56(28.6)$ \\
\hline Total & $\mathbf{2 3 2}$ & $\mathbf{1 5 9}$ \\
\hline
\end{tabular}

Prevalence of smoking in MBBS students was found to be $15.2 \%$. The prevalence of alcohol consumption was found to be $20.3 \%$ (17.6\% occasional and $2.4 \%$ daily drinkers). On comparing the substance abuse habit between the different categories of students, it was observed that smoking and alcohol intake was more common in post graduate students $(28.6 \%$ \& $48.1 \%$ respectively) followed by interns $(24.6 \%$ \& $32.1 \%)$ and less among undergraduates $(15.2 \% \&$ $20.4 \%)$

\section{Discussion}

Substance abuse (tobacco, alcohol, and various other drugs) have been recognized as an area of concern among medical students. In the present study majority of the participants were Hindu (95.8\%) and $73.4 \%$ belonged to nuclear family. There were $49.6 \%$ males and $50.5 \%$ females. $62.1 \%$ subjects were undergraduates, followed by Post graduates $(24.1 \%)$ and Interns (13.8\%). Considering current residential details; subjects residing in hostel were present in greater number (77.5\%) This was similar to the study done by 
Baba $\mathrm{T}$ et $\mathrm{al}^{(7)}$ where majority of substance abusers lived in hostels (37\%) . This can explained by the reason where majority of them got access to substances through friends which they meet in hostels.

In the present study the prevalence of smoking in MBBS students is found to be $15.2 \%$ which is similar to the with the smoking prevalence $(15 \%)$ of the general population of India. ${ }^{(8)}$ The prevalence of alcohol consumption was found to be $20.3 \%$ (17.6\% occasional and $2.4 \%$ daily drinkers) which is supported by the study done by Apoorva et $\mathrm{al}^{(9)}$ on college students too reported a prevalence of $26.4 \%$ alcohol consumption. On comparing the substance abuse habit between the different categories of students, it was observed that smoking and alcohol intake was more common in post graduate students $(28.6 \%$ \& $48.1 \%$ respectively) followed by interns $(24.6 \%$ \& $32.9 \%)$ and less among undergraduates $(15.2 \% \&$ 20.4\%). Similarly, study conducted by Majra $\mathrm{JP} 17^{(10)}$ in a pilot study on two medical colleges also observed an increase in the smoking and alcohol consumption prevalence in the fourth year medical students $26.2 \%$ and $43.8 \%$ respectively.

\section{Conclusion}

Majority of the students were non-smokers and about one fourth were consuming alcohol. Drug dependence is significantly higher in post graduate students as compared to under graduates. The roots of this problem runs deep into our society and may contribute to other factors like depression, communicable diseases and social evils. The problem of substance abuse among the medical students should be taken more seriously as their own attitudes towards substances may have impact on their profession.

\section{Acknowledgement: None}

\section{References}

1. Substance abuse, Geneva: World Health Organization: 2015, Available from URL http://www .who. int/ substance_abuse /facts/ global_burden/en/ (assessed on 2010-2015).

2. Datta A, Bhattacharyya A, Naskar NN. A Study of Substance Abuse among Medical students Kolkata. Indian $\mathrm{J}$ Hygiene and Public Health. 2015;1(2):41-47.

3. Mcewen BS. Physiology and neurobiology of stress and adaptation: central role of the brain. Physiological Reviews. 2007; 87(3):873-904.

4. K. Devi, Rohan Patel, Ashok M.Phil. Study of Psychological Depression and its associated factors among Medical Students in Pondic-herry. Indian Journal of Basic \& Applied Medical Research 2013; 2 (8): 1009-1016

5. AN Supe. A study of stress in medical students at Seth G.S. Medical College. JPGM 1998; 44 (1): 1-6.

6. Hafferty FW. Beyond curriculum reform: confronting medicine's hidden curriculum. Acad Med 1998; 73 (4):403-7.

7. Baba TA, Ganai AM, Quadri SS, Margoob MA, Ibbal QM, Khan ZA. An epidemiological Study on Substance Abuse Among college Students of North India (Kashmir Valley). Int J Med Sci Public Health. 2013;2(3):562-7

8. World Health Organization. Noncommunicable diseases and mental health. Noncommunicable Diseases Country Profiles, 2014. Available at http://www.who.int/nmh/ publications/ncdprofiles-2014/en/. Accessed on November 10th 2014.

9. Apoorva, Arjun S. Pillai, Arjun Nayanar et al. Risk factors and consequences of alcohol consumption among college students. NUJHS 2014; 4(2).

10. Majra JP. Do Our Medical Colleges Inculcate Health- Promoting Lifestyle Among Medical Students: A Pilot Study from Two Medical Colleges from Southern India. Int J Prev Med. 2013; 4(4): 425-429. 